\title{
Proximate Determinants and Decomposition of Changes in Fertility Levels in Nigeria, 2003-2018
}

\section{Tubosun Alex Olowolafe ( $\square$ tubosun.olowolafe@gmail.com )}

Tehran University of Medical Sciences Department of Epidemiology and Biostatistics https://orcid.org/0000-0002-6312-3038

\section{Ayo Stephen Adebowale}

University of Ibadan College of Medicine

Adeniyi Francis Fagbamigbe

University of Ibadan Faculty of Public Health

Joshua Odunayo Akinyemi

University of Ibadan Faculty of Public Health

Obiageli Chiezey Onwusaka

University of Ibadan Faculty of Public Health

\section{Research}

Keywords: Proximate determinants, Change in fertility level, Decomposition, Nigeria

Posted Date: December 4th, 2020

DOI: https://doi.org/10.21203/rs.3.rs-119069/v1

License: (c) (i) This work is licensed under a Creative Commons Attribution 4.0 International License.

Read Full License 
Proximate Determinants and Decomposition of Changes in Fertility Levels in Nigeria, 20032018

\section{Tubosun Alex Olowolafe ${ }^{1 *}$, Ayo Stephen Adebowale ${ }^{1}$, Adeniyi Francis Fagbamigbe ${ }^{1}$, Joshua Odunayo Akinyemi ${ }^{1}$, Obiageli Chiezey Onwusaka ${ }^{1,2}$}

${ }^{1}$ Department of Epidemiology and Medical Statistics, Faculty of Public Health, College of Medicine, University of Ibadan, Ibadan, Nigeria

${ }^{2}$ Department of Public Health, Faculty of Allied Medical Sciences, University of Calabar, Calabar, Nigeria

* Corresponding author:

tubosun.olowolafe@gmail.com (T. A. Olowolafe)

\section{Abstract}

Background: There is disparity in fertility level across the six geopolitical zones in Nigeria. Deeper uunderstanding about the drivers of fertility trends are necessary to prioritize zonal specific strategies for fertility reduction in Nigeria. Thus, this study examined the proximate determinants (PDs) of fertility and decomposed the change in its level across the six geo-political zones in Nigeria.

Method: Data from Nigeria Demographic and Health Surveys of 2003 and 2018 were analyzed. Fertility data were based on the report of full birth history from women of reproductive age. The Revised Bongaarts framework was used to estimate PDs and fertility levels. The contribution of each PDs to the observed changes in fertility levels was quantified using Das Gupta's five- factor decomposition method.

Result: Across the zones, there was a change in the fertility inhibiting effect of Contraception $(\mathrm{Cc})$ between 2003 and 2018. The fertility inhibiting effect of Postpartum Infecundability (Ci) and Abortion was the highest and smallest respectively across the zones. The Total fertility rate (TFR) in 2003 and 2008 across the zones are South-South (5.04 vs 4.36), South-West (4.88 vs 4.26), North West (7.25 vs 6.85), North East (6.87 vs 6.54), North Central (5.72 vs 5.48), South East (5.06 vs 4.86 ), Nigeria (6.00 vs 5.59). Delayed sexual exposure $(\mathrm{Cm})$ and contraceptive use $(\mathrm{Cc})$ contributed the most to the change across the regions. The percentage contribution of $\mathrm{Cm}$ in SouthSouth, South West, and South East was 87.04\%, 52.89\%, and 172.85\% respectively. Furthermore, most of the fertility change observed in North Central was attributable to Cc.

Conclusion: Abortion index was not an important inhibiting factor of fertility in Nigeria. Delayed sexual exposure and contraceptive use accounted for the largest change observed in fertility levels across the six geo-political zones in Nigeria between 2003 and 2018. Strategies that promote delayed sexual exposure, contraceptive use and breast feeding practices will enhance fertility transition in Nigeria.

Keywords: Proximate determinants, Change in fertility level, Decomposition, Nigeria 


\section{Background}

Fertility level, often measure by the total fertility rate (TFR), indicates the reproductive behaviour of a woman if the prevailing age specific fertility rates (ASFR) is sustained throughout her reproductive years [1]. Fertility level of a country has an effect on its population size, structure and growth rate [2] and often used to determine replacement level [3, 41]. Globally, the level of fertility dropped from 5.3 children per woman in 1900 to about 2.5 children per woman in 2019 [4]. The levels of fertility in developed regions of the world had been consistently less than two children per woman between 1990 and 2019 [5, 6]. The fertility rates have been found to be below replacement level in countries like Ireland (1.98), France (1.85), US (1.89), Australia (1.83), China (1.64), South Korea (1.33), Singapore (1.26) and Taiwan (1.22) [5].

A decline in fertility level was observed between 1990 and 2019 in Central and Southern Asia (4.3 to 2.4), Northern Africa (4.4 to 2.9), Latin America (3.3 to 2.2), and in Oceania (4.5 to 3.4). Over the same period, the level of fertility also decreased from above 6.3 children per woman to 4.6 children per woman in sub-Saharan Africa [6]. The world fertility level has been predicted to drop from 2.5 to 1.9 children per woman by 2100 . However, the decline in fertility to replacement level is not expected to end in Africa soon. African countries, especially those in the sub-Saharan region, have persistently recorded the highest level of fertility among the world sub-regions [7].

However, some countries in Africa has begun fertility transition. These include Tunisia (2.1), Libya (2.2), Cape Verde (2.3), Seychelles (2.3), and South Africa (2.4) [9]. However, Nigeria $(\mathrm{TFR}=5.3)$, the most populous country in Africa with a population estimate of above 200 million [10], is among the top ten high fertility countries in the region [9]. In Nigeria, fertility level has been declining gradually from above six live births per woman in 1990 to above five live births in 2018 [11, 12, 13, 14]. However, variation exists in fertility levels across the regions in Nigeria. According to NDHS reports, the North West (6.6) has the highest and South West (3.9) has the lowest. With this high fertility rates in Nigeria, the country is expected to lag behind in terms of achieving the replacement level in the years ahead.

In Nigeria, many factors such as ethnicity, religion, education, age at first birth e.t.c. have been identified as fertility predictors [43]. However, in practice, no single factor can explain the fertility behavior of a particular country [17]. Due to multifaceted- determinants of fertility, many theories 
have been proposed to describe fertility behavior. The approaches to fertility is not restricted to economical, socio-cultural, psychological, and biological and behavioral determinants [18]. This prompted Bongaarts to model fertility causative factors as proximate determinants (PDs) based on the natural fertility ideology. He proposed that the level of fertility in any population can be determined by the proportion of women of reproductive age that is married, the effective use of contraception, induced abortion, postpartum infecundability, the frequency of intercourse, the onset of permanent sterility, and spontaneous intrauterine mortality. He argued that the proposition that a woman may likely bear at least fifteen children during her lifetime could be reduced via modification of each of these factors $[19,20]$. Thus suggesting that a change in any of the PDs of fertility will directly affect fertility, even if others remain constant. Accordingly, fertility variations and trends can be attributed to changes in at least one of the PDs [21].

Several studies across the world have applied this Bongaart's framework in the analysis of fertility. Alene and Worku (2009) reported that the fertility-inhibiting effect of postpartum infecundability which was as a result of prolonged breastfeeding was the most important proximate determinant in Ethiopia [22]. A study conducted in Malaysia found that delay in marriage and uptake of contraceptive was the most important proximate determinants of fertility; while postpartum infecundability and abortion played a part in explaining ethnic fertility differentials [23]. To study the changes in fertility across sub-Saharan Africa, Madhavan (2014) analyzed the contributions of the proximate determinants of fertility to overall fertility decline by country and found increasein the proportions of unmarried women and contraceptive use as major factors responsible for fertility decline in SSA [24]. A Bangladesh study identified contraceptive use as a leading PDs in fertility change [25]. Across Asia countries, changing marriage pattern and induced abortion were key in reducing fertility among poor women [26]. Marriage and postpartum infecundabiliity were found to account for the highest inhibiting effect of natural fertility in Zambia [27]. Recently, programmes that would promote contraceptive use and breast feeding practices were recommended for rapid fertility decline among Ethiopia women [28].

In Nigeria, increased use of contraception and changes in marriage pattern were found to be associated with the fertility decline [17]. Another study concluded that the richest in Nigeria compared to the poorest were depending more on delayed marriage and contraception for fertility reduction $[29,30]$. Also fertility has been estimated at both national and across the six geopolitical 
zones in Nigeria by previous studies $[12,13,14,15,16,44]$. The studies focused mainly on the use of direct and indirect approaches to fertility estimation. However, estimating fertility level at sub-national regions will require appropriate consideration for PDs of fertility due to cultural diversities and socioeconomic differences in the six-geopolitical zones in Nigeria. Unfortunately, there is limited research evidence about which of the PDs has highest contribution to recent change in fertility level in each of these Nigerian geo-political zones. With several campaigns and programmes targeted at encouraging breastfeeding, increasing contraceptives use and female education, it is imperative to examine how these activities have contributed to the fertility transition in each of the six regions in Nigeria. A country of multi-ethnic nature like Nigeria where the level of fertility at the national level may be grossly inadequate to provide clear understanding about factors explaining fertility changes will require a sub-group analysis. The study's outcome will provide more insights into the drivers of fertility trends that are required to prioritize strategies for fertility reduction across the geopolitical zones in Nigeria. We, therefore, aimed to estimate the PDs and decompose the change in fertility level between 2003 and 2018 across the six geo-political zones of Nigeria.

\section{METHODS AND DATA}

\section{Method and data}

Nigeria comprises of 36 states with a Federal Capital Territory, and structured into six geopolitical zones which are North Central, North East, North West, South East, South-South and South West. Nigeria has the largest population in Africa and 14th largest in land mass [14]. According to the 2006 Population and Housing Census conducted in Nigeria, the country's population was $140,431,790$, but the 2019 projection based on the 2006 census figure as the base year was above 200 million [10]. Nigeria is a multi-ethnic country with the three major ethnic groups being; Hausa/Fulani, Igbo and Yoruba and cultural practices among all the ethnic groups favour childbearing. However, the level of fertility varies due to cultural diversities and differential in some sociocultural factors that influence fertility [15]. Polygamy is very common among the Muslims and early marriage is prevalent in the Northern part of Nigeria. Nigeria is being considered as developing nation characterized by high poverty rate and low literacy level. 


\section{Study design and data}

The study utilized data from the 2003 and 2018 Demographic and Health Survey (NDHS). This was a cross- sectional and nationally representative survey of Nigerian households with a stratified representative sample that cut across all the six geopolitical zones. The 2003 survey used the sampling frame from the 1991 population census while the sampling frame from the 2006 population and housing census was employed for 2018 survey. The number of households interviewed in 2003 and 2018 was 7864 and 42000 respectively. The number of women aged 1549 years interviewed for these surveys was 7620 and 41821 respectively $[11,14]$. Sample weights were applied to each case to adjust for differences in the probability of selection. Weighting is important in to increase the extent of representativeness in the sample and to reduce the errors associated with sample selection bias.

\section{Data Analysis}

We used revised Bongaarts's proximate determinants (PDs) of fertility model and Das Gupta's five factor decomposition method to analyse the data. Bongaart framework estimated total fertility rate (TFR) as the product of four indices quantifying the fertility inhibiting effect and the total fecundity (TF) which is the average number of live births born to a woman, if she remains married throughout her reproductive years, in the absence of contraception, and no any induced abortion and if she does not breastfeed her children [20]. The four main PDs are marriage, contraception, abortion and postpartum infecundity. The indicator for each PDs ranges from 0 to 1 with smaller values showing greater effects and 1 indicating no inhibiting effect. The model assumes that the TF is almost the same for all women but the actual fertility is affected by the four main PDs. The TF to a Nigerian woman was estimated to be 14 [21]. 


\section{Original Bongaarts Framework and Equation}

\begin{tabular}{|l|l|l|}
\hline $\begin{array}{l}\text { Parameters of Bongaarts } \\
\text { Framework }\end{array}$ & Equation & Variable \\
\hline Marriage Index & $C_{m}=\frac{\sum m(a) f_{m}(a)}{\sum f_{m}(a)}$ & $\begin{array}{l}\mathrm{m}(\mathrm{a})=\text { proportion married by } \\
\text { age; } \mathrm{f}_{\mathrm{m}}(\mathrm{a})=\text { age specific } \\
\text { marital fertility rate; } \mathrm{a}=\text { age }\end{array}$ \\
\hline Contraception Index & $C_{c}=1-1.08 u e$ & $\begin{array}{l}\mathrm{u}=\text { contraceptive prevalence } \\
\text { (married women); }=\text { average } \\
\text { effectiveness }\end{array}$ \\
\hline $\begin{array}{l}\text { Postpartum Infecundability } \\
\text { index }\end{array}$ & $C_{i}=\frac{20}{18.5+i}$ & $\begin{array}{l}\text { i }=\text { average duration of } \\
\text { postpartum infecundability }\end{array}$ \\
\hline Abortion Index & $C_{a}=\frac{T F R}{T F R+b T A R}$ & $\begin{array}{l}\text { TFR = total fertility rate; TAR } \\
= \\
\text { total abortion rate; } \mathrm{b}=\text { births } \\
\text { averted per abortion }\end{array}$ \\
\hline Total Fecundity Rate $(\mathrm{TF})$ & $b=0.4(1+u)$ & \\
\hline TFR = $\mathrm{C}_{\mathrm{m}} \mathrm{C}_{\mathrm{c}} \mathrm{C}_{\mathrm{i}} \mathrm{C}_{\mathrm{a}} \mathrm{TFR}$ & & \\
\hline
\end{tabular}

\section{Source: Bongaart (2015)}

\section{The Revised Bongaart Proximate Determinants of Fertility Model}

The analysis in this study was based on the revised Bongaart model [21]. The revision was made to the original model due to issues raised by Stover [31]. The revised model replaced the index of marriage or cohabitation with index of sexual exposure. The number of women who are exposed to the risk of childbearing was estimated by aggregating the number of women who married women (or in consensual unions) and unmarried women who are pregnant, report sex in the last month and use contraception. The index of contraception was revised by allowing variation in effectiveness by age and method. No revision was needed for Postpartum Infecundability Index. The abortion index was estimated using abortion rate produced by Sedgh and colleagues [32], because of a paucity of information on abortion in developing countries [21]. The estimates of TAR were 30 times abortion rate per 1000 . 
We used the following notations:

$\mathrm{TAR}=$ Total abortion rate

$\mathrm{TF}=$ total fecundity rate

$\mathrm{f}_{\mathrm{f}}(\mathrm{a})=$ fecundity rate

$\mathrm{f}_{\mathrm{m}}(\mathrm{a})=$ fertility rate exposed women

$f_{n}(a)=$ natural exposed fertility,

$\mathrm{m}(\mathrm{a})=$ proportion $\mathrm{married} / \mathrm{union}$

$x(a)=$ extramarital exposure

$\mathrm{u}(\mathrm{a})=$ contraception prevalence (exposed women)

$o(a)=$ overlap with postpartum infecundability

$\mathrm{e}(\mathrm{a})=$ average effectiveness

$r=$ fecundity adjustment

$\mathrm{i}(\mathrm{a})=$ average duration of postpartum infecundability

$\operatorname{ar}(\mathrm{a})=$ abortion rate, $\mathrm{a}=$ age

The first step was the calculation of proximate determinants of fertility for each time period (equations 1-12 below) as proposed by Bongaarts [21]:

$$
T F R=C_{m} C_{c} C_{i} C_{a} T F
$$

$\mathrm{C}_{\mathrm{m}}$ is sexual exposure index

$$
\begin{aligned}
& C_{m}=\sum C_{m}(a) W_{m}(a) \\
& C_{m}(a)=m(a)+x(a) \\
& W_{m}(a)=\frac{f_{m}(a)}{\sum f_{m}(a)} \\
& f_{m}(a)=C c(a) C_{i}(a) C_{a}(a) f_{f}(a)
\end{aligned}
$$

$\mathrm{C}_{\mathrm{c}}$ is contraception index

$$
\begin{gathered}
C c=\sum C c(a) W c(a) \\
C_{c}(a)=1-r(a)(u(a)-o(a)) e(a) \\
W c(a)=\frac{f_{n}(a)}{\sum f_{n}(a)} \approx \frac{f_{f}(a)}{f_{f}(a)}
\end{gathered}
$$


$\mathrm{C}_{\mathrm{i}}$ is Postpartum Infecundability Index

$$
\begin{gathered}
C_{i}=\sum C_{i}(a) W_{i}(a) \\
C_{i}(a)=\frac{20}{18.5+i(a)}
\end{gathered}
$$

Abortion Index

$$
\begin{aligned}
C_{a} & =\sum C_{a}(a) W_{a}(a) \approx \frac{T F R}{T F R+b T A R} \\
b & =\frac{14}{18.5+i(a)}
\end{aligned}
$$

Direct method developed by Moultrie and colleagues was used to produce the total fertility rates (TFR). The mathematical exposition of this method has been published elsewhere [42]

\section{Change in Estimated TFR}

The indices of the four major PDs were estimated for the 2003 and 2018 with assumption that TF was 14. Then, equation (1) was used to estimate TFR for both 2003 and 2018 in order to derive the change in Estimated TFR. Thereafter, we decomposed the change in estimated TFR between time periods to determine the contributions of each index to this change.

\section{Decomposition of the change in Estimated TFR}

A five- factor decomposition method proposed by Das Gupta [33] was used to decompose the change in estimated TFR between 2003 and 2018. The description of the method is as follows:

If $\mathrm{T}_{1}=\mathrm{TFR}_{2003}$ and $\mathrm{a}_{1}, \mathrm{~b}_{1}, \mathrm{c}_{1}, \mathrm{~d}_{1}, \& \mathrm{e}_{1}$ represent $\mathrm{Cm}, \mathrm{Cc}, \mathrm{Ci}, \mathrm{Ca} \& \mathrm{TF}$ of 2003 respectively

$\mathrm{T}_{2}=\mathrm{TFR}_{2018}$ and $\mathrm{a}_{2}, \mathrm{~b}_{2}, \mathrm{c}_{2}, \mathrm{~d}_{2}, \& \mathrm{e}_{2}$ represent $\mathrm{Cm}, \mathrm{Cc}, \mathrm{Ci}, \mathrm{Ca} \& \mathrm{TF}$ of 2018 respectively

The change in TFR

$\mathrm{T}_{2}-\mathrm{T}_{1}=\mathrm{a}$-effect $+\mathrm{b}$-effect $+\mathrm{c}$-effect $+\mathrm{d}$-effect $+\mathrm{e}$-effect

$\mathrm{a}-\mathrm{effect}=\mathrm{Q}\left(\mathrm{a}_{2}-\mathrm{a}_{1}\right)$

Where $Q$ is a function of $b_{1}, c_{1}, d_{1}, e_{1} b_{2}, c_{2}, d_{2}, e_{2}$ given by: 
$Q=\frac{b_{2} c_{2} d_{2} e_{2}+b_{1} c_{1} d_{1} e_{1}}{5}+\frac{b_{2} c_{2} d_{2} e_{1}+b_{2} c_{2} d_{1} e_{2}+b_{2} c_{1} d_{2} e_{2}+b_{1} c_{2} d_{2} e_{2}+b_{1} c_{1} d_{2} e_{2}+b_{1} c_{2} d_{1} e_{1}+b_{2} c_{1} d_{1} e_{1}}{20}$

$+\frac{b_{2} c_{2} d_{1} e_{1}+b_{2} c_{1} d_{1} e_{1}+b_{2} c_{1} d_{1} e_{2}+b_{1} c_{1} d_{2} e_{2}+b_{1} c_{1} d_{2} e_{2}+b_{1} c_{2} d_{1} e_{2}+b_{1} c_{2} d_{2} e_{1}}{30}$

$\mathrm{b}$-effect $=\mathrm{Q}\left(\mathrm{b}_{2}-\mathrm{b}_{1}\right)$

Where $Q$ is a function of $a_{1}, c_{1}, d_{1}, e_{1}, a_{2}, c_{2}, d_{2}, e_{2}$ given by:

$Q=\frac{a_{2} c_{2} d_{2} e_{2}+a_{1} c_{1} d_{1} e_{1}}{5}+\frac{a_{2} c_{2} d_{2} e_{1}+a_{2} c_{2} d_{1} e_{2}+a_{2} c_{1} d_{2} e_{2}+a_{1} c_{2} d_{2} e_{2}+a_{1} c_{1} d_{2} e_{2}+a_{1} c_{2} d_{1} e_{1}+a_{2} c_{1} d_{1} e_{1}}{20}$

$+\frac{a_{2} c_{2} d_{1} e_{1}+a_{2} c_{1} d_{1} e_{1}+a_{2} c_{1} d_{1} e_{2}+a_{1} c_{1} d_{2} e_{2}+a_{1} c_{1} d_{2} e_{2}+a_{1} c_{2} d_{1} e_{2}+a_{1} c_{2} d_{2} e_{1}}{30}$

d-effect $=Q\left(d_{2}-d_{1}\right)$

Where $Q$ is a function of $a_{1}, b_{1}, d_{1}, e_{1}, a_{2}, b_{2}, d_{2}, e_{2}$ given by:

$Q=\frac{a_{2} b_{2} c_{2} e_{2}+a_{1} b_{1} c_{1} e_{1}}{5}+\frac{a_{2} b_{2} c_{2} e_{1}+a_{2} b_{2} c_{1} e_{2}+a_{2} b_{1} c_{2} e_{2}+a_{1} b_{2} c_{2} e_{2}+a_{1} b_{1} c_{2} e_{2}+a_{1} b_{2} c_{1} e_{1}+a_{2} b_{1} c_{1} e_{1}}{20}$

$+\frac{a_{2} b_{2} c_{1} e_{1}+a_{2} b_{1} c_{1} e_{1}+a_{2} b_{1} c_{1} e_{2}+a_{1} b_{1} c_{2} e_{2}+a_{1} b_{1} c_{2} e_{2}+a_{1} b_{2} c_{1} e_{2}+a_{1} b_{2} c_{2} e_{1}}{30}$

e-effect $=Q\left(e_{2}-e_{1}\right)$

Where $\mathrm{Q}$ is a function of $\mathrm{a}_{1}, \mathrm{~b}_{1}, \mathrm{c}_{1}, \mathrm{~d}_{1}, \mathrm{a}_{2}, \mathrm{~b}_{2}, \mathrm{c}_{2}, \mathrm{e}_{2}$ given by:

$Q=\frac{a_{2} b_{2} c_{2} d_{2}+a_{1} b_{1} c_{1} d_{1}}{5}+\frac{a_{2} b_{2} c_{2} d_{1}+a_{2} b_{2} c_{1} d_{2}+a_{2} b_{1} c_{2} d_{2}+a_{1} b_{2} c_{2} d_{2}+a_{1} b_{1} c_{2} d_{2}+a_{1} b_{2} c_{1} d_{1}+a_{2} b_{1} c_{1} d_{1}}{20}$
$+\frac{a_{2} b_{2} c_{1} d_{1}+a_{2} b_{1} c_{1} d_{1}+a_{2} b_{1} c_{1} d_{2}+a_{1} b_{1} c_{2} d_{2}+a_{1} b_{1} c_{2} d_{2}+a_{1} b_{2} c_{1} d_{2}+a_{1} b_{2} c_{2} d_{1}}{30}$

\section{Result}

Figure 1 illustrates the trends in total fertility rates resulting from the direct estimation method. The results, according to the figure, show a marginal decline in Nigeria; a persistence but slow decline in North Central. In South-East, it appears fertility rose between 2003 and 2008, but stalled between 2008 and 2018. Also, an accelerated fertility decline was observed in South-South compared to other regions. Inconsistences were observed in North West and South West. However, the level of fertility has been consistently lowest in the South West, and highest in the North West, except in 2003 where North East was highest and in 2013 where South-South was lowest. 


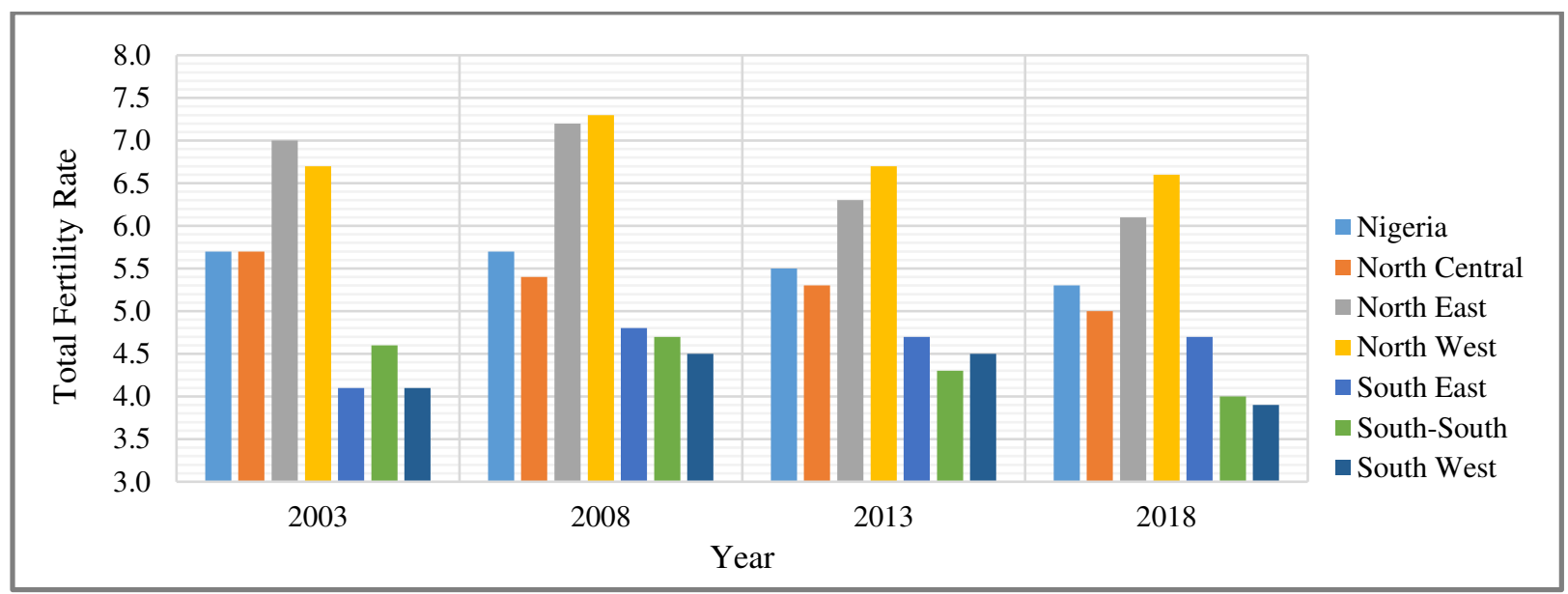

Figure 1: Trend in Total Fertility Rates in Nigeria and Regions 2003- 2018

Table 1 shows the estimated proximate determinants and total fertility rate by regions and Nigeria, 2003 \& 2018. As indicated in the table, the Estimated TFR based on estimated proximate determinants for Nigeria and regions are as follows: Nigeria 2003 (6.0), Nigeria 2018 (5.59), North Central 2003 (5.72), North Central 2018 (5.48), North East 2003 (6.87), North East 2018 (6.54), North West 2003 (7.25), North West 2018 (6.85), South East 2003 (5.06), South East 2018 (4.86), South-South 2003(5.04), South-South 2018 (4.36), South West 2003 (4.88), South West 2018 (4.26). In 2003, fertility inhibiting effect of Postpartum Infecundity was the greatest in Nigeria (0.69); North Central (0.67), North East (0.68), North West (0.68) and South-South (0.72). However, in the South East, it was a delay in sexual exposure (0.70); and it was contraceptive use in South West (0.70). In 2018, the pattern remained nearly the same in the Northern region and South-East; but it was a delay in sexual exposure that has highest inhibiting effects on fertility in South West (0.68) and South-South (0.65). Notably, the abortion rate has the smallest fertility inhibiting effect across the regions. 
Table 1: Estimated Proximate Determinants and Total Fertility Rate (TFR) for Region and Nigeria, 2003 \& 2018

\begin{tabular}{|c|c|c|c|c|c|c|}
\hline $\begin{array}{l}\text { Regions by } \\
\text { Survey years }\end{array}$ & $\begin{array}{c}\text { Sexual } \\
\text { Exposure } \\
\text { Index }\end{array}$ & $\begin{array}{l}\text { Contraception } \\
\text { Index }\end{array}$ & $\begin{array}{l}\text { Postpartum } \\
\text { Inf. index }\end{array}$ & $\begin{array}{l}\text { Abortion } \\
\text { Index }\end{array}$ & $\begin{array}{c}\text { Total } \\
\text { Fecundity }\end{array}$ & $\begin{array}{c}\text { Estimated } \\
\text { TFR }\end{array}$ \\
\hline Nigeria 2003 & 0.7938 & 0.8324 & 0.6898 & 0.9409 & 14 & 6.00 \\
\hline Nigeria 2018 & 0.7691 & 0.7950 & 0.7040 & 0.9281 & 14 & 5.59 \\
\hline North Central 2003 & 0.7951 & 0.8148 & 0.6689 & 0.9430 & 14 & 5.72 \\
\hline North Central 2018 & 0.7791 & 0.7826 & 0.69442 & 0.9242 & 14 & 5.48 \\
\hline North East 2003 & 0.8315 & 0.9111 & 0.6791 & 0.9540 & 14 & 6.87 \\
\hline North East 2018 & 0.8639 & 0.8384 & 0.6845 & 0.9426 & 14 & 6.54 \\
\hline North West 2003 & 0.8877 & 0.9017 & 0.6774 & 0.9546 & 14 & 7.25 \\
\hline North West 2018 & 0.8830 & 0.8462 & 0.6981 & 0.9378 & 14 & 6.85 \\
\hline South East 2003 & 0.7048 & 0.7711 & 0.7174 & 0.9265 & 14 & 5.06 \\
\hline South East 2018 & 0.6572 & 0.7659 & 0.7569 & 0.9107 & 14 & 4.86 \\
\hline South-South 2003 & 0.7386 & 0.7330 & 0.7195 & 0.9251 & 14 & 5.04 \\
\hline South-South 2018 & 0.6491 & 0.7266 & 0.7318 & 0.9023 & 14 & 4.36 \\
\hline South West 2003 & 0.7331 & 0.7000 & 0.7347 & 0.9251 & 14 & 4.88 \\
\hline South West 2018 & 0.6812 & 0.6822 & 0.7282 & 0.9002 & 14 & 4.26 \\
\hline
\end{tabular}

Inf.: Infecundity

Table 2 shows the decomposition of changes in estimated TFR for Regions and Nigeria, 20032018. According to the result, change in TFR between 2003 and 2018 across the regions are given as follows from highest to the lowest: South-South (-0.68), South West (-0.62), North West (0.40), North West (-0.33), North Central (-0.24) and South East (-0.20) as well as Nigeria (-0.41). Sexual exposure index and contraceptive use contributed the most to the change across the regions. For instance, the percentage contribution of sexual exposure in South-South, South West, South East, and Nigeria were $87.04 \%, 52.89 \%, 172.85 \%$ and $43.53 \%$ respectively. However, it is worthy of note that the contraceptive use reduced between 2003 and 2018 in North West. Furthermore, most of the change observed in North central (92.04\%) and Nigeria (63.31\%) was attributable to contraceptive use. 
Table 2: Decomposition of Change in TFR by Regions and Nigeria, 2003-2018

\begin{tabular}{|c|c|c|c|c|c|c|c|}
\hline $\begin{array}{l}\text { Regions by } \\
\text { Survey years }\end{array}$ & $\begin{array}{l}\text { Est. } \\
\text { TFR }\end{array}$ & $\begin{array}{c}\text { Change } \\
\text { in Est. } \\
\text { TFR }\end{array}$ & $\begin{array}{c}\text { Sexual } \\
\text { Exposure } \\
\text { effect } \\
(\% \mathrm{CB}) \\
\end{array}$ & $\begin{array}{c}\text { Contraception } \\
\text { effect } \\
(\% \mathrm{CB})\end{array}$ & $\begin{array}{c}\text { Postpartum } \\
\text { Infecundability } \\
\text { effect } \\
(\% \mathrm{CB})\end{array}$ & $\begin{array}{c}\text { Abortion } \\
\text { effect } \\
(\% \mathrm{CB})\end{array}$ & $\begin{array}{c}\text { Residual } \\
(\% \mathrm{CB})\end{array}$ \\
\hline Nigeria 2003 & 6.00 & -0.41 & -0.18012 & -0.26196 & 0.116093 & -0.07805 & -0.0097 \\
\hline Nigeria 2018 & 5.59 & & 43.53 & 63.31 & -28.06 & 18.86 & 2.35 \\
\hline North Central 2003 & 5.72 & -0.24 & -0.11192 & -0.22202 & 0.20593 & -0.11108 & -0.0021 \\
\hline North Central 2018 & 5.48 & & 46.40 & 92.04 & -85.37 & 46.05 & 0.89 \\
\hline North East 2003 & 6.87 & -0.33 & 0.271535 & -0.54953 & 0.052318 & -0.07977 & -0.0262 \\
\hline North East 2018 & 6.54 & & -81.87 & 165.69 & -15.77 & 24.05 & 7.90 \\
\hline North West 2003 & 7.25 & -0.40 & -0.03678 & -0.44021 & 0.20851 & -0.12328 & -0.0049 \\
\hline North West 2018 & 6.85 & & 9.27 & 110.97 & -52.56 & 31.08 & 1.24 \\
\hline South East 2003 & 5.06 & -0.20 & -0.34108 & -0.03299 & 0.261906 & -0.08397 & -0.0012 \\
\hline South East 2018 & 4.86 & & 172.85 & 16.72 & -132.74 & 42.56 & 0.58 \\
\hline South-South 2003 & 5.04 & -0.68 & -0.59608 & -0.04048 & 0.078255 & -0.11506 & -0.0115 \\
\hline South-South 2018 & 4.36 & & 87.04 & 5.91 & -11.43 & 16.80 & 1.67 \\
\hline South West 2003 & 4.88 & -0.62 & -0.32947 & -0.11559 & -0.03988 & -0.1223 & -0.0156 \\
\hline South West 2018 & 4.26 & & 52.89 & 18.56 & 6.40 & 19.64 & 2.51 \\
\hline
\end{tabular}

Est.: Estimated; TFR: Total Fertility Rate; CB: Contribution; Est.: Estimated

\section{Discussion}

Our study estimated the proximate determinants of fertility and fertility level as well as decomposed the changes in fertility levels across the six geopolitical zones of Nigeria between 2003 and 2018. The estimated TFRs for Nigeria in 2003 (6.0) and 2018 (5.6) were inconsistent with that of NDHS reports but not too different from the estimates obtained by an international study [36]. However, the change of 0.4 observed was the same with the change documented in the NDHS 2018 report [14]. The estimates across the regions as indicated in the study- North Central 2003 (5.7), North Central 2018 (5.5), North East 2003 (6.9), North East 2018 (6.5), North West 2003 (7.3), North West 2018 (6.9), South East 2003 (5.1), South East 2018 (4.9), South-South 2003(5.0), South-South 2018 (4.4), South West 2003 (4.9), South West 2018 (4.3)- are plausible estimates [23]. The level of fertility was highest in the North West and lowest in South West, and this pattern was consistent in 2003 and 2018. This finding is in line with earlier studies conducted in Nigeria [14,15]. The northern region dominated by people of Hausa/Fulani origin, mainly illiterates and predominantly Muslim. These groups have been marked as fertility drivers in Nigeria. 
The findings of this study identified three proximate determinants of fertility that have played important roles in Nigeria's fertility level in 2003 and 2018. In both 2003 and 2018, fertility inhibiting effect of Postpartum Infecundity was the greatest in Nigeria, North Central, North West and North East. While, in South East, South-South and South West it was delayed sexual exposure and contraception use that were greatest inhibitor of natural fertility. This indicates that postpartum infecundability (breastfeeding), delayed sexual exposure, and contraception are important predicators of fertility outcome in Nigeria. These results were similar to findings in Malaysia, Bangladesh, Ghana, Zambia, Namibia, and Ethiopia [23, 25, 27, 28, 34, 35]. The fertility-inhibiting effects of contraceptive use and sexual exposure increased in Nigeria between 2003 and 2018. In $2003, \mathrm{C}_{\mathrm{c}}$ was 0.8324 but decreased to 0.7850 in 2018; while a minimal changed was observed in $\mathrm{C}_{\mathrm{m}}$ between 2003 (0.7938) and 2018 (0.7691). The change in $\mathrm{C}_{\mathrm{c}}$ reflected an increase in contraceptive use prevalent rate among Nigeria reproductive women as documented in NDHS reports [14].

Based on the result of this model the highest change was observed in South-South (-0.68) and lowest in South East (-0.20). The huge change observed in South-South compares to other regions may not be unconnected with literacy level (ability to read and write) which was the highest in the region [14] and decline of under-five mortality was more rapid in the region compared to other regions [37]. However, meagre change noticed in South East remains a puzzle that needs a second look because reproductive women of South-South and South East have similar characteristics.

The results of the decomposition presented in this study show that the change observed in the level of fertility was majorly caused by delayed sexual exposure and contraception use. This finding corroborates the studies that have established the importance of contraceptive use and age at first sexual debut in facilitating fertility reduction $[27,38,39]$. The contribution of sexual exposure to change observed in TFRs of Southern regions between 2003 and 2018 reflects postponement in the age of first marriage. This is not surprising in Southern region of Nigeria because of women with a higher level of education. Women's education affects fertility via postponement of the onset of childbearing and contraceptive use [40]. Furthermore, the results of this study also revealed that the little change observed in the Northern region was majorly due to a marginal increase in the prevalent of Contraceptive use in the regions [14]. Given the relatively early marriage that persists in the North West and North East, the fertility level remains above six. 


\section{Implications for policy and future research}

Nigeria, with a population estimate of above 200 million and growth rate of about $2.5 \%$, is among the ten topmost fertility level in the world. The unrestraint population growth of Nigeria may have harmful implication for the country's health, environment, and infrastructural development. Analysis of fertility across sub-national in a heterogeneous country like Nigeria is necessary considering its importance on accomplishment of sustainable development goals. The different drivers of fertility found in this study are necessary to prioritize strategies for fertility reduction across the zones of Nigeria. In the quest to facilitate a rapid reduction in Nigeria fertility level, researches that will focus on the needed change in each of the PDs for drastic decline in fertility level across the zones of Nigeria will be a welcome development.

\section{Limitation}

Theoretically, Bongaarts PDs framework is strong; however, it is limited by paucity of data on some of the PDs such as sexual activities, the effectiveness of contraceptive use, and abortion rate. Estimating these PDs accurately has remained hard.

\section{Conclusion}

Out of the four proximate determinants of fertility, only abortion index appears to be an unimportant inhibiting factor of fertility across the six geo-political zones of Nigeria. At the national level, postpartum infecundability has the highest fertility inhibiting effect. While, the greatest fertility inhibiting effect was postpartum infecundability in the northern region, sexual exposure and contraceptive were the greatest inhibitors on natural fertility in the southern region. The Bongaart's models adopted in this study provided plausible estimates of fertility level and clearly show the change in fertility level between 2003 and 2018 across the six geo-political zones in Nigeria. This study has also revealed that fertility levels are still high in Nigeria. There were regional differentials in fertility levels and trends. The driver of fertility level in Nigeria remain North West and North East. Notably, Southern regions are moving to the point of transiting to the second phase of transition that is where TFR equals 4.0; while, fertility levels are above 6 children per woman in North West and North East. The decomposition analysis revealed that delayed sexual exposure and contraceptive use contributed the largest chunk of the change observed in fertility level in Nigeria between 2003 and 2018. Strategies and programmes that will promote delayed 
sexual exposure, contraceptive use and breast feeding practices among the reproductive women are imperative to accelerate fertility transition in Nigeria.

\section{Ethical Approval and Consent to Participate}

The study was based on the secondary data which were assessed on the web platform of the data originators. The data originators sought informed consents from the respondents and they were assured of confidentiality and anonymity of the information they provide. There was no identifier in the raw data that can be used to link a particular respondent to the information she provides. Proper approval to download and use NDHS data was obtained from ORC Macro International, the agency responsible for Demographic and Health survey globally.

\section{Consent for publication}

Not Applicable

\section{Availability of data and materials}

The data utilized for this paper can be found at http://dhsprogram.com. The data is accessible to the public but permission to use the data is required. The authors obtained permission from the data owners to use the data.

\section{Competing interests}

The authors declare that they have no competing interests.

\section{Funding}

The authors receive no support or funding for this study.

\section{Authors' contributions}

TAO and ASA conceived and designed the study; TAO analyzed the data and wrote the results; TAO and OCO reviewed the literature and prepared the manuscript. ASA AFF and JOA reviewed and edited the manuscript. All authors read and consented to the final version of the manuscript 


\section{Authors' Information}

TAO is a Doctoral Student at the Department of Epidemiology and Medical Statistics, College of Medicine, Ibadan, University of Ibadan, Nigeria. ASA is a Senior Lecturer and Demographer at the Department of Epidemiology and Medical Statistics, College of Medicine, Ibadan, University of Ibadan, Nigeria. AFF is a Senior Lecturer and Medical Statistician at the Department of Epidemiology and Medical Statistics, College of Medicine, Ibadan, University of Ibadan, Nigeria. JOA is a Senior Lecturer and Medical Statistician at the Department of Epidemiology and Medical Statistics, College of Medicine, Ibadan, University of Ibadan, Nigeria. OCO is a Doctoral Student at the Department of Epidemiology and Medical Statistics, College of Medicine, Ibadan, University of Ibadan, Nigeria and a Lecturer at the Department of Public Health, Faculty of Allied Medical Sciences, University of Calabar, Calabar, Nigeria.

\section{Acknowledgments}

The authors appreciate ICF Macro, USA, for free access to the data.

\section{References}

1. Rowland, D. T. 2003. Fertility and the family Demographic Methods and Concepts (pp. 220-250). New York: Oxford university Press.

2. Akinyemi, A. I. and Isiugo-abanihe, U. C. 2014. Demographic dynamics and development in Nigeria : Issues and perspectives. African Population Studies, 27(Mar), pp. 239-248.

3. Kirkt, D. 1996. Demographic Transition Theory. Population Studies. 50 (2), pp. 361-387. DOI: $10.1080 / 0032472031000149536$

4. Ghosh, I. 2019. Visualizing over a Century of Global Fertility. Available at https://www.visualcapitalist.com/over-a-century-of-global-fertility/.

5. World Population Review. 2020. 2020 world population by country. Available at https://worldpopulationreview.com

6. United Nations, Department of Economic and Social Affairs, Population Division. World Population Prospects 2019: Highlights (ST/ESA/SER.A/423). Available at https://population.un.org/wpp/

7. Shapiro, D. and Hinde, A. 2017. On the pace of fertility decline in sub-Saharan Africa. Demographic Research: Volume 37, Article 40, Pages 1327-1338. DOI: 10.4054/DemRes.2017.37.40.

8. United Nations, Department of Economic and Social Affairs, Population Division 2020. World Fertility and Family Planning: Highlights. Available at https://www.unpopulation.org 
9. World Bank. 2019. Fertility Rate, total (births per women). Available at https://data.worldbank.org/indicator/SP.DYN.TFRT.IN?locations=IN

10. Population Reference Bureau. 2019. World Population Data Sheet. Washington, DC: PRB.

11. National Population Commission (NPC) [Nigeria] and ORC Macro. (2004). Nigeria Demographic and Health Survey 2003. Calverton, Maryland: National Population Commission and ORC Macro.

12. National Population Commission (NPC) [Nigeria] and ICF Macro. (2009). Nigeria Demographic and Health Survey 2008. Abuja, Nigeria: National Population Commission and ICF Macro.

13. National Population Commission (NPC) [Nigeria] and ICF International. (2014). Nigeria Demographic and Health Survey 2013. Abuja, Nigeria: National Population Commission and ICF International.

14. National Population Commission (NPC) [Nigeria] and ICF International. (2019). Nigeria Demographic and Health Survey 2018. Abuja, Nigeria: National Population Commission and ICF International.

15. Adebowale A.S. 2019. Ethnic disparities in fertility and its determinants in Nigeria. BMC Fertility Research and Practice (2019)5:3. https://doi.org/10.1186/s40738-019$\underline{0055-\mathrm{y}}$

16. Alaba, O.O., Olubusoye, O. E. and Olaomi, J.O. 2017. Spatial patterns and determinants of fertility levels among women of childbearing age in Nigeria. South African Family Practice; 59(4):143-147. https://doi.org/10.1080/20786190.2017.1292693

17. Feyisetan, B. J. and Bankole, A. 2002. Fertility Transition In Nigeria : Trends And Prospect. In United Nations, Department of Economic ans Social Affairs, Population Division (Ed.), Completing the fertility transition. New York, USA: United Nations

18. Huinink, J, Kohli, M. and Ehrhardt, J. 2015. Explaining fertility: The potential for integrative approaches. Demographic Research. 33(4): 93-112. DOI:10.4054/DemRes.2015.33.4.

19. Bruijn, B. J. D. E. 2006. Models, Concepts and Development of Fertility. Population Studies, pp. 549-569.

20. Bongaarts J. A framework for analysing the proximate determinants of fertility. Popul Dev Rev. 1978;4(1):105-32. https://doi.org/10.2307/1972149

21. Bongaarts, J. 2015. Modeling the fertility impact of the proximate determinants: Time for a tune-up. Demographic Research. 33(19): 535-560. DOI: 10.4054/DemRes.2015.33.19

22. Alene, G. D. and Worku, A. 2009. Estimation of the total fertility rates and proximate determinants of fertility in North and South Gondar zones, Northwest Ethiopia: An application of the Bongaarts' model. Ethiop.J.Health Dev. 2009;23(1):19-27.

23. Tey, N. P., Ng, S. T. and Yew, S. Y. 2012. "Proximate determinants of fertility in peninsular Malaysia," Asia-Pacific Journal of Public Health, vol. 24, no. 3, pp. 495-505.

24. Madhavan S. 2014. An Analysis of the Proximate Determinants of Fertility in SubSaharan Africa with A Focus on Induced Abortion. Baltimore: JHU.

25. Islam, M. N., Hossain, M. G., Karim, M. R., Islam, M. R., Lestrel, P. E., Islam, M. A. 2014. Fertility analysis of Bangladesh population using the revised Bogart's model. Advances Life Sci.;4(2):44-51.

26. Majumder, N. and Ram, F. 2015. Explaining the role of proximate determinants on fertility decline among poor and non-poor in Asian countries. PLoS One; 10(2): e0115441. https://doi.org/10.1371/journal.pone.0115441. 
27. Chola, M. and Michelo, C. 2016. Proximate determinants of fertility in Zambia: Analysis of the 2007 Zambia Demographic and Health Survey. International Journal of Population Research, 2016: 1-7.

28. Laelago, T., Habtu, Y. and Yohannes, S. 2019. Proximate determinants of fertility in Ethiopia; an application of revised Bongaarts model. BMC: Reproductive Health (2019) 16:13. https://doi.org/10.1186/s12978-019-0677-X

29. Finlay, J. E., Mejía-Guevara, I., Akachi, Y. 2016. Delayed marriage, contraceptive use, and breastfeeding: Fertility patterns over time and wealth quintiles in sub-Saharan Africa. WIDER Working Paper, No. 2016/43, ISBN 978-92-9256-086-7, The United Nations University World Institute for Development Economics Research (UNUWIDER),Helsinki, http://dx.doi.org/10.35188/UNU WIDER/2016/086-7

30. Finlay, J. E., Mejía-Guevara, I., Akachi, Y. 2018. Inequality in total fertility rates and the proximate determinants of fertility in 21 sub-Saharan African countries. PLoS ONE 13(9): e0203344. https://doi.org/10.1371/journal.pone.0203344.

31. Stover, J. 1998. Revising the proximate determinants of fertility framework: What have we learned in the past 20 years? Studies in Family Planning, 29(3), 255-267.

32. Sedgh, G., Singh S., Shah, I., Åhman, E., Henshaw S., and Bankole, A. 2012b. Induced abortion: Incidence and trends worldwide from 1995 to 2008. The Lancet 379(9816): 625632. doi:10.1016/S0140-6736(11)61786-8.

33. Das Gupta, P. 1989. Methods of decomposing the difference between two rates with applications to race-sex inequality in earnings. Mathematical Population Studies, 2(1), 15-36, 89.

34. Rutaremwa, G., Galande, J., Nviiri, H. L., Akiror, E. and Jhamba, T. 2015. The contribution of contraception, marriage and postpartum insusceptibility to fertility levels in Uganda: an application of the aggregate fertility model. Fertil Res Pract. ;1:16.

35. Palamuleni, M. E. 2017. Determinants of fertility decline in Namibia: an analysis of the proximate determinants. Bangladesh e-J Sociol.;14(2):41-63.

36. Nigeria Population (2020)- Worldometer. https://www.worldometers.info/worldpopulation/nigeria-population/

37. Akinyemi, J. O., Adebowale, A. S., Bamgboye, E. A., and Ayeni, O. 2015. Child survival dynamics in Nigeria: Is the 2006 Child Health Policy Target Met? Nigerian Journal of Health Sciences, 15(1), 18-26.

38. Acharya, A. K. 2010. The influence of female age at marriage on fertility and child loss in India. Trayectorias, 12(31), 61-80.

39. Bongaarts, J. 2017. Africa's unique fertility transition. Population and Development Review, 43(S1), 39-58.

40. Shapiro, D. 2012. Women's education and fertility transition in sub-Saharan Africa. Vienna Yearbook of Population Research, Vol 10: 9-30.

41. Sullivan, J. N. O. 2013. Revisiting demographic transition : correlation and causation in the rate of development and fertility decline. pp. 1-12.

42. Moultrie, T. A., Dorrington, R. E., Hill A. G., Hill, K., Timæus, I. M., Zaba, B., editors. 2013. Tools for demographic estimation. Paris: International Union for the Scientific Study of Population. demographicestimation.iussp.org

43. Adebowale, A. S., Asa, S., Abe, J. O., and Oyinlola, F. F. 2019. Sex Preference, Religion and Ethnicity Roles in Fertility among Women of Childbearing Age in Nigeria: 
Examining the Links using Zero-Inflated Poisson Regression Model. International Journal of Statistics and Probability; Vol 8, No. 6. DOI:10.5539/ijsp.v8n6p91

44. Adebowale, A.S., Fagbamigbe, A. F., Akinyemi, J. O, Olowolafe, T., Onwusaka, O. Adewole, D., Sadiku, S. and Palamuleni, M. 2020. Dynamics of poverty-related dissimilarities in fertility in Nigeria: 2003-2018. Scientific African 9 (2020) e00468. https://doi.org/10.1016/j.sciaf.2020.e00468 
Figures

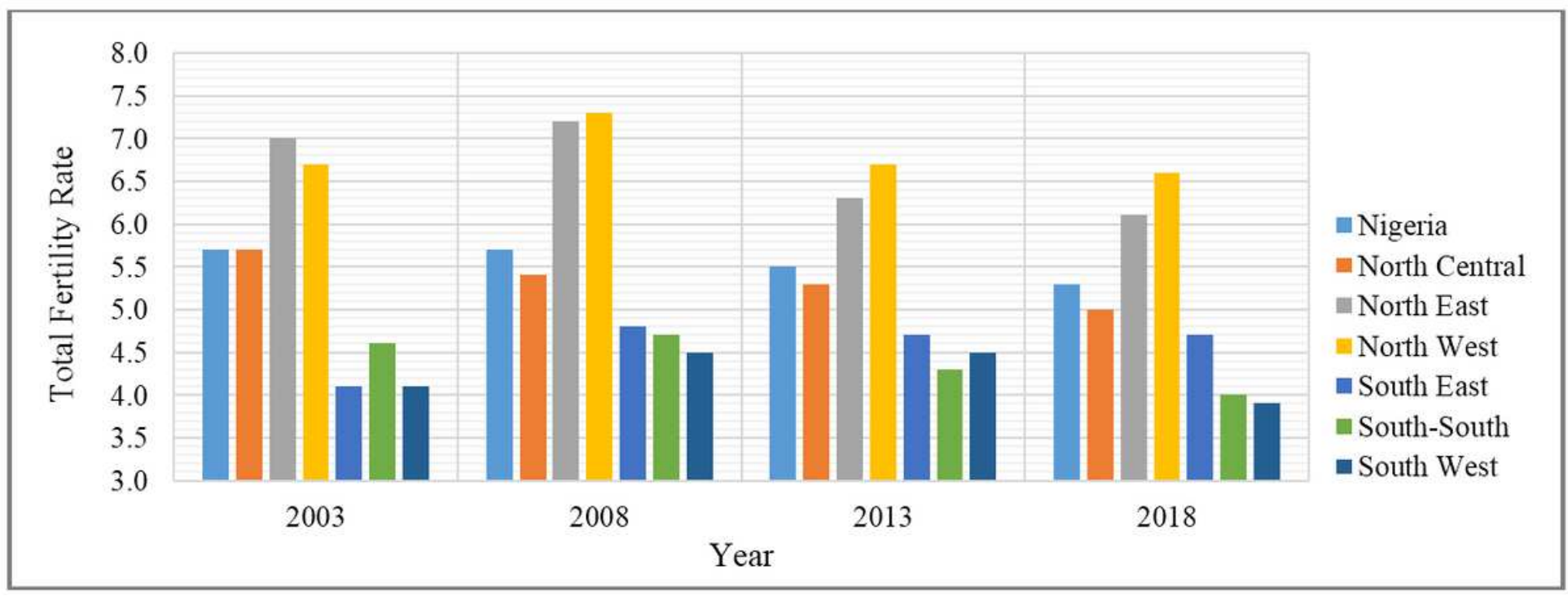

Figure 1

Trend in Total Fertility Rates in Nigeria and Regions 2003- 2018 